Lux: Maassanalytische Werthbestimmung der Bleimennige.

Resultat · · · · $29,6 \% \mathrm{PO}_{5}$
Molybdänmethode . . $29,53 \ll$

$2 g$ eines andern Phosphates, in gleicher Weise behandelt. $10 c c$ verlangten in 3 Proben je $14,7 \mathrm{cc}$.

$\begin{array}{lllll}\text { Resultat . . . . . } & 23,5 \% & \mathrm{PO}_{5} \\ \text { Molybdänmethode } & \text {. } & 23,61 & \ll & \ll\end{array}$

Der Gehalt der Mineralien an Eisenoxyd betrug $4 \%$.

Maassanalytische Werthbestimmung der Bleimennige. Von

\title{
Friedrich Lux.
}

Bleisuperoxyd mit einer wässerigen Lösung von Oxalsäure im Ueberschuss übergossen, zersetzt sich mit derselben voliständig in Bleioxyd, Kohlensäure und Wasser nach der Formel

$$
\mathrm{Pb} \theta_{2}+\mathrm{C}_{2} \mathrm{H}_{2} \theta_{4}=\mathrm{Pb} \theta+2 \mathrm{CO}_{2}+\mathrm{H}_{2} \theta \text {. }
$$

Das durch die überschüssige Oxalsäure gebildete oxalsaure Bleioxyd wird von verdünnter Salpetersäure in der Wärme leicht gelöst und es kann nun in dieser salpetersauren Lösung die überschüssige Oxalsäure leicht bestimmt werden.

Diese Methode in Verbindung mit derjenigen, Blei durch saures chromsaures Kali in essigsaurer Lösung zu titriren, ermöglicht eine rasche und für die Praxis genügend genaue Werthbestimmung der Blejmennige. Das hierbei von mir angewandte Verfahren ist folgendes:

2,07g der zu untersuchenden Mennige werden in einer ca. $300 c c$ fassenden Porzellanschale mit einer nicht $\mathrm{zu}$ geringen Menge (20-30 cc) verdünnter Salpetersäure übergossen und unter Umrühren gelinde erwärmt; nach einigen Minuten ist die Mennige in sich lösendes Bleioxyd und ungelöstes Bleisuperoxyd zerlegt. Man setzt nun $50 \mathrm{cc}$ einer $1 / 5$ Normaloxalsäurelösung $\left(12,6 g \mathrm{C}_{2} \mathrm{H}_{2} \theta_{4}+2 \mathrm{H}_{2} \theta\right.$ im Liter $)$ zu und erhitzt zum Sieden. Das Bleisuperoxyd wird sofort zerlegt und gelöst, und man erkennt jetzt schon an der Beschaffenheit der Flüssigkeit in gewissem Grad die Qualität der Mennige. Schwerspath, schwefelsaures Bleioxyd, Thon, Sand, Eisenoxyd und grössere Mengen Gyps werden sich 
durch Trübung resp. Absatz zu erkennen geben, während reine Mennige eine völlig farblose, klare Lösung gibt.

Man erhält die Flüssigkeit im Sieden und bestimmt, unbekümmert darum, ob dieselbe klar oder getrübt ist. mit $1 / 5$ Normalchamäleonlösung, welche genau auf die Oxalsäurelösung eingestellt ist, die überschüssige Oxalsäure. Die Anzahl gebrauchter Cubikcentimeter Chamäleonlösung werden von 50 abgezogen, die Differenz ergibt in Procenten das als Superoxyd vorhandene Blei. -

Es ist hierbei zu bemerken, dass die Zersetzung der Oxalsäure durch Chamäleon in $\mathrm{x}$ e in salpetersaurer Lösung und bei Gegenwart von Blei etwas langsamer von Statten geht, wie in mit Schwefelsäure versetzter Lösung; so bleibt die durch die ersten paar Tropfen Chamäleon bewirkte Rothfärbung selbst in der Siedhitze längere Zeit bestehen, verschwindet dann bei weiterem Zusatz rasch, um gegen Ende der Operation wieder langsamer zu vergehen. Ich erhielt indessen auf folgende Weise immer übereinstimmende Resultate: Man setzt, da höchstens 30,21 \% Blei als Superoxyd vorhanden sein können, demnach mindestens $19,79 c c$ Oxalsäurelösung unzersetzt geblieben sind, sofort $5-10 \mathrm{cc}$ Chamäleonlösung zu; die Entfärbung tritt dann sofort ein, ebenso bei weiterem Zusatz von Chamäleon, bis sie gegen Ende langsamer verläuft. Man betrachtet die Titration als beendet, wenn die durch 2 Tropfen Chamäleon bewirkte Rosafärbung innerhalb einer $1 / 2$ Minute nicht völlig verschwunden ist. -

Nachdem die Flüssigkeit durch einige Minuten langes Kochen oder durch einen Tropfen Oxalsäurelösung entfärbt ist, wird dieselbe mit Ammoniak bis fast zur Neutralisation, dann mit essigsaurem Ammon oder Natron in genügender Menge versetzt und in bekannter Weise mit Chromatlösung, welche im Liter $14,761 g \mathrm{~K}_{2} \operatorname{Gr}_{2} \theta_{7}$ enthält, titrirt. Die Anzahl verbrauchter Cubikcentimeter gibt in Procenten den Gesammtbleigehalt. Wird von diesem das als Superoxyd vorhandene Blei abgezogen, so bleibt die als oxyd vorhandene Bleimenge, und es lässt sich nun leicht die Zusammensetzung der Meunige berechnen.

Die Bestimmung des Bleisuperoxyds wird durch keine der etwa vorhandenen Verunreinigungen oder Verfälschungen beeinträchtigt, diejenige des Gesammtbleigehalts ebenfalls nicht, ausser bei Anwesenheit von kohlensaurem Baryt (Witherit), dem ich allerdings bis jetzt hier noch nicht begegnete. Findet daher beim Uebergiessen der Mennige mit Salpetersäure eine stärkere Gasentwickelung statt (eine sehr ge- 
ringe, yon etwas kohlensaurem Bleioxyd oder Kalk herrührend, ist fast immer zu bemerken), so ist zunächst die An- oder Abwesenheit von Baryt zu constatiren. Es geschieht dies in einfachster Weise durch Vebergiessen einer Probe Mennige mit Salpetersäure, Abfiltriren vom Bleihyperoxyd, Versetzen des Filtrates mit Sclowefelsäure, Befreien des Niederschlags vom grössten Theil der sauren Lösung durch Decantation, Versetzen mit Ammoniak bis zur alkalischen Reaction und Zusatz von weinsaurem Ammon: Reines Bleisulfat löst sich vollständig, Baryumsulfat bleibt, zurück.

Zum Schluss theile ich die Resultate einiger von mir nach dieser Methode ausgeführten Untersucbungen von Mennige mit, welche u. A. darthun, wie sehr die meisten Mennigsorten des Handels, abgesehen von den Verunreinigungen (Nichtbleiverbindungen), von der theoretischen Zusammensetzung $\mathrm{Pb}_{3} \Theta_{4}$ entfernt sind.

\begin{tabular}{|c|c|c|c|c|c|c|c|c|c|c|c|c|c|c|c|c|}
\hline $\mid \begin{array}{l}\phi^{+\infty} \\
0^{\infty} \\
\rho^{+\infty}\end{array}$ & 1 & 2 & 3 & 4 & 5 & 6 & 7 & 8 & 9 & 10 & 11 & 12 & 13 & 14 & 15 & 16 \\
\hline 34,89 & 33,6 & 26,7 & 26,5 & 24,7 & 24,7 & 24,3 & 23,5 & 23,4 & 23,0 & 22,7 & 22,4 & 20,5 & 20,4 & 18,9 & 18,3 & 17,5 \\
\hline 65,11 & 65,0 & 70,3 & 71,9 & 69,9 & 73,4 & 69,0 & 70,9 & 69,4 & 64,1 & 71,1 & 64,1 & 71,7 & 75,6 & 77,2 & 73,5 & 75,1 \\
\hline- & 1,4 & 3,0 & 1,6 & 5,4 & 1,9 & 6,7 & 5,6 & 7,2 & 12,9 & 6,2 & 13,5 & 7,8 & 4,0 & 3,9 & 8,2 & 7,4 \\
\hline 100,0 & 100,0 & 100,0 & 100,0 & 100,0 & 100,0 & 100,0 & 100,0 & 100,0 & 100,0 & 100,0 & 100,0 & 100,0 & 100,0 & 100,0 & 100,0 & 100,0 \\
\hline 100 & 96,3 & 76,5 & 75,9 & 70,8 & 70,8 & 69,6 & 67,4 & 67,1 & 65,9 & 65,0 & 61,2 & 58,7 & 58,5 & 54,2 & 52,4 & 50 \\
\hline- & 2,3 & 20,5 & 22,5 & 23,8 & 27,3 & 23,7 & 27,0 & 25,7 & 21,2 & 28,8 & 22,3 & 33,5 & 37,5 & 41,9 & 39,4 & 42,5 \\
\hline- & 1,4 & 3,0 & 1,6 & 5,4 & 1,9 & 6,7 & 5,6 & 7,2 & 12,9 & 6,2 & 13,5 & 7,8 & 4,0 & 3,9 & 8,2 & 7, \\
\hline 100 & $.00,0$ & $0, \mathrm{C}$ & 0.0 & 100,0 &, 0 & 100,0 & &, 0 & 1002 & 100,0 & & 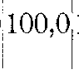 & & $\mathrm{J}$, & 100 & \\
\hline
\end{tabular}

Ludwigshafen a/Rh. im December 1879. 